\title{
Endoscopic tissue sampling - Part 1: Upper gastrointestinal and hepatopancreatobiliary tracts. European Society of Gastro- intestinal Endoscopy (ESGE) Guideline
}

Authors

Roos E. Pouw ${ }^{1}$, Maximilien Barret ${ }^{2}$, Katharina Biermann³ ${ }^{3}$ Raf Bisschops ${ }^{4}$, László Czakó5 ${ }^{5}$, Krisztina B. Gecse ${ }^{6}$, Gert de Hertogh $^{7}$, Tomas Hucl ${ }^{8}$, Marietta lacucci ${ }^{9}$, Marnix Jansen ${ }^{10}$, Matthew Rutter ${ }^{11} \odot$, Edoardo Savarino ${ }^{12} \odot$, Manon C. W. Spaander ${ }^{13}$ (๑) Peter T. Schmidt ${ }^{14}$, Michael Vieth ${ }^{15}$, Mário Dinis-Ribeiro ${ }^{16}$, Jeanin E. van Hooft ${ }^{17}$ 이

Institutions

1 Department of Gastroenterology and Hepatology, Amsterdam Gastroenterology Endocrinology Metabolism, Cancer Center Amsterdam, Amsterdam University Medical Centers location VUmc, Amsterdam, The Netherlands

2 Department of Gastroenterology and Digestive Oncology, Cochin Hospital and University of Paris, Paris, France

3 Department of Pathology, Erasmus Medical Center, Rotterdam, The Netherlands

4 Department of Gastroenterology and Hepatology, University Hospitals Leuven, Leuven, Belgium

5 First Department of Medicine, University of Szeged, Szeged, Hungary

6 Department of Gastroenterology and Hepatology, Amsterdam University Medical Centers location AMC, Amsterdam, The Netherlands

7 Department of Pathology, University Hospitals Leuven, Leuven, Belgium

8 Institute for Clinical and Experimental Medicine, Prague, Czech Republic

9 Institute of Translational Medicine, Institute of Immunology and Immunotherapy and NIHR Birmingham Biomedical Research Centre, University Hospitals NHS Foundation Trust and University of Birmingham, Birmingham, UK

10 Department of Histopathology, University College London Hospital, London, UK

11 Department of Gastroenterology, University Hospital of North Tees, Stockton-on-Tees, UK

12 Department of Surgery, Oncology and Gastroenterology, University of Padua, Padua, Italy

13 Department of Gastroenterology and Hepatology, Erasmus University Medical Center, Rotterdam, The Netherlands
14 Department of Medicine (Solna), Karolinska Institute and Department of Medicine, Ersta Hospital, Stockholm, Sweden

15 Institute of Pathology, Friedrich-Alexander University Erlangen-Nuremberg, Klinikum Bayreuth, Bayreuth, Germany

16 Department of Gastroenterology, Portuguese Oncology Institute of Porto, Porto, Portugal

17 Department of Gastroenterology and Hepatology, Leiden University Medical Center, Leiden, The Netherlands

published online 17.9 .2021

Bibliography

Endoscopy 2021; 53: 1174-1188

DOI 10.1055/a-1611-5091

ISSN 0013-726X

(C) 2021. European Society of Gastrointestinal Endoscopy

All rights reserved.

This article is published by Thieme.

Georg Thieme Verlag KG, Rüdigerstraße 14,

70469 Stuttgart, Germany

丹 Table 1s

Supplementary material is available under https://doi.org/10.1055/a-1611-5091

Corresponding author

Roos E. Pouw, MD PhD, Dept. of Gastroenterology and Hepatology, Amsterdam University Medical Centers, location VUmc, De Boelelaan 1118, 1081 HZ Amsterdam,

The Netherlands

r.e.pouw@amsterdamumc.nl 


\section{MAIN RECOMMENDATIONS}

1 ESGE recommends that, where there is a suspicion of eosinophilic esophagitis, at least six biopsies should be taken, two to four biopsies from the distal esophagus and two to four biopsies from the proximal esophagus, targeting areas with endoscopic mucosal abnormalities. Distal and proximal biopsies should be placed in separate containers. Strong recommendation, low quality of evidence.

2 ESGE recommends obtaining six biopsies, including from the base and edge of the esophageal ulcers, for histologic analysis in patients with suspected viral esophagitis.

Strong recommendation, low quality of evidence.

3 ESGE recommends at least six biopsies are taken in cases of suspected advanced esophageal cancer and suspected advanced gastric cancer.

Strong recommendation, moderate quality of evidence.

4 ESGE recommends taking only one to two targeted biopsies for lesions in the esophagus or stomach that are potentially amenable to endoscopic resection (Paris classification $0-I, 0-I I)$ in order to confirm the diagnosis and not compromise subsequent endoscopic resection.

Strong recommendation, low quality of evidence.

5 ESGE recommends obtaining two biopsies from the antrum and two from the corpus in patients with suspected Helicobacter pylori infection and for gastritis staging.

Strong recommendation, low quality of evidence.
6 ESGE recommends biopsies from or, if endoscopically resectable, resection of gastric adenomas.

Strong recommendation, moderate quality of evidence.

7 ESGE recommends fine-needle aspiration (FNA) and fineneedle biopsy (FNB) needles equally for sampling of solid pancreatic masses.

Strong recommendation, high quality evidence.

8 ESGE suggests performing peroral cholangioscopy (POC) and/or endoscopic ultrasound (EUS)-guided tissue acquisition in indeterminate biliary strictures. For proximal and intrinsic strictures, $\mathrm{POC}$ is preferred. For distal and extrinsic strictures, EUS-guided sampling is preferred, with POC where this is not diagnostic.

Weak recommendation, low quality evidence.

9 ESGE suggests obtaining possible non-neoplastic biopsies before sampling suspected malignant lesions to prevent intraluminal spread of malignant disease.

Weak recommendation, low quality of evidence.

10 ESGE suggests dividing EUS-FNA material into smears (two per pass) and liquid-based cytology (LBC), or the whole of the EUS-FNA material can be processed as LBC, depending on local experience.

Weak recommendation, low quality evidence.

\section{SOURCE AND SCOPE}

This Guideline is an official statement of the European Society of Gastrointestinal Endoscopy (ESGE). It provides guidance on the collection and handling of tissue samples during endoscopy of the upper gastrointestinal and hepatopancreatobiliary tracts. The Grading of Recommendations Assessment, Development and Evaluation (GRADE) system was adopted to define the strength of recommendations and the quality of evidence.

\section{Introduction}

Adequate collection and handling of tissue samples during endoscopy is fundamental in diagnosing pathology of the digestive system. The aim of this guideline was to make evidence-based recommendations on the indications and protocols for endoscopic tissue sampling for the most common conditions in the upper and lower gastrointestinal tracts and the hepatopancreatobiliary (HPB) tract (the lower gastrointestinal tract will be covered in Part 2 and published separately).

\section{Methods}

The European Society of Gastrointestinal Endoscopy (ESGE) commissioned this Guideline (Guideline Committee chair, J.v.H.) and appointed a guideline leader (R.P.) who invited the listed authors to participate in the project development. After the project group had been assembled, task forces were formed to define the key questions and PICOs (population, intervention, comparator, outcome) in the upper gastrointestinal, lower gastrointestinal, and HPB domains (Table $1 \mathrm{~s}$, see online-only Supplementary material). Literature searches and reviews of the relevant articles were performed between March and September 2020. The available evidence was graded according to the Grading of Recommendations Assessment, Development and Evaluation (GRADE) system [1]. Based on the available evidence, recommendations and suggestions were drafted and discussed with the project group during online meetings. Further details on the methodology of ESGE guideline development have been reported elsewhere [2].

In February 2021, a draft prepared by the leaders and coordinating team was sent to all group members. The manuscript was also reviewed by two independent reviewers and sent for further comments to the ESGE National Societies and individual 


$\begin{array}{ll}\text { ABBREVIATIONS } \\ \text { CMV } & \text { cytomegalovirus } \\ \text { ERCP } & \begin{array}{l}\text { endoscopic retrograde cholangiopancreato- } \\ \text { graphy }\end{array} \\ \text { ESGE } & \text { European Society of Gastrointestinal Endoscopy } \\ \text { EUS } & \text { endoscopic ultrasound } \\ \text { FGP } & \text { fundic gland polyp } \\ \text { FNA } & \text { fine-needle aspiration } \\ \text { FNB } & \text { fine-needle biopsy } \\ \text { GERD } & \text { gastroesophageal reflux disease } \\ \text { GRADE } & \text { Grading of Recommendations Assessment, } \\ & \text { Development and Evaluation } \\ \text { HIV } & \text { human immunodeficiency virus } \\ \text { HPB } & \text { hepatopancreatobiliary } \\ \text { HSV } & \text { herpes simplex virus } \\ \text { LBC } & \text { liquid-based cytology } \\ \text { MALT } & \text { mucosa-associated lymphoid tissue } \\ \text { MAPS } & \text { management of precancerous conditions and } \\ & \text { lesions in the stomach } \\ \text { PICO } & \text { population, intervention, comparator, and } \\ & \text { outcome } \\ \text { POC } & \text { peroral cholangioscopy } \\ \text { PPI } & \text { proton pump inhibitor } \\ \text { ROSE } & \text { rapid onsite evaluation }\end{array}$

members. After agreement on a final version, including the agreed recommendations (a summary of the upper gastrointestinal tract recommendations is given in > Table $\mathbf{1}$ ), the manuscript was submitted to the journal Endoscopy for publication. All authors agreed on the final revised manuscript.

This Guideline was issued in 2021 and will be considered for review and update in 2026 , or sooner if new and relevant evidence becomes available. Any updates to the Guideline in the interim will be noted on the ESGE website: http://www.esge. com/esge-guidelines.html.

\section{Upper gastrointestinal tract}

\subsection{Eosinophilic esophagitis}

\section{RECOMMENDATION}

ESGE recommends that, where there is a suspicion of eosinophilic esophagitis, at least six biopsies should be taken, two to four biopsies from the distal esophagus and two to four biopsies from the proximal esophagus, targeting areas with endoscopic mucosal abnormalities. Distal and proximal biopsies should be placed in separate containers.

Strong recommendation, low quality of evidence.

Biopsies should be obtained in patients in whom eosinophilic esophagitis is a clinical possibility, even when normal mucosa is visualized. Inflammatory alterations in eosinophilic esophagitis are frequently patchy, therefore it is recommended that at least six biopsies should be obtained from at least two different locations in the esophagus, typically two to four biopsies from both the distal and proximal esophagus, depending on where most endoscopic abnormalities are visualized. The diagnostic sensitivity increases with the number of biopsies and is maximized with at least six biopsies. Esophageal biopsies should be targeted to areas of endoscopic abnormality, mainly white stipples, exudates, and longitudinal furrows, which are associated with higher eosinophil counts. In patients with symptoms, biopsies should also be taken even if the endoscopic appearance is normal, as this has been reported in up to $10 \%$ of adult patients [3-7].

\section{RECOMMENDATIONS}

ESGE suggests, in histologically confirmed eosinophilic esophagitis, obtaining biopsies after a 6- to 12-week initial treatment course, with at least two to four biopsies from the distal esophagus and two to four biopsies from the proximal esophagus, focusing on areas with endoscopic mucosal abnormalities.

Weak recommendation, very low quality of evidence.

ESGE suggests against endoscopy and histologic assessment on an annual basis for patients who have responded to therapy and are maintained on these treatments.

Weak recommendation, very low quality of evidence.

For patients who are treated with a proton pump inhibitor (PPI), elimination diet, or steroids, the response to therapy can be assessed by means of a follow-up endoscopy after a 6- to 12week initial course, obtaining at least six biopsies from at least two different locations in the esophagus, typically two to four biopsies from both the distal and proximal portions of the esophagus. However, there is little evidence to support this in patients who respond to therapy. For patients who respond to a PPI, elimination diet, or steroids and are maintained on these treatments, current data do not support follow-up with endoscopic and histologic assessment [3-7].

\subsection{Gastroesophageal reflux disease}

\section{RECOMMENDATION}

ESGE recommends against obtaining biopsies for the diagnosis of gastroesophageal reflux disease (GERD) in patients with normal endoscopic findings.

Strong recommendation, low quality of evidence.

In patients with complaints of gastroesophageal reflux, with or without PPI use, and with or without endoscopic signs of erosive esophagitis, biopsies are not recommended to confirm gastroesophageal reflux disease (GERD). For this indication, 
- Table 1 Summarized recommendations for tissue sampling in the upper gastrointestinal tract.

\begin{tabular}{|c|c|c|}
\hline Suspected diagnosis or indication & Number and location of biopsies & Remarks \\
\hline $\begin{array}{l}\text { Eosinophilic esophagitis: initial } \\
\text { diagnosis or evaluation of therapy } \\
\text { response }\end{array}$ & $\begin{array}{l}\text { At least six biopsies, two to four biopsies from the distal esophagus and } \\
\text { two to four biopsies from the proximal esophagus, targeting areas with } \\
\text { endoscopic mucosal abnormalities }\end{array}$ & $\begin{array}{l}\text { Place biopsies from the distal } \\
\text { and proximal esophagus into } \\
\text { separate containers }\end{array}$ \\
\hline Gastroesophageal reflux disease & Biopsies not indicated for diagnosis & \\
\hline \multicolumn{3}{|l|}{ Infectious esophagitis } \\
\hline - Candida esophagitis & $\begin{array}{l}\text { Given the high positive predictive value of white plaque-like lesions for } \\
\text { candida, biopsies are only indicated if the results would have therapeutic } \\
\text { consequences }\end{array}$ & $\begin{array}{l}\text { Mycologic analysis only in- } \\
\text { dicated for treatment resist- } \\
\text { ance }\end{array}$ \\
\hline - Viral esophagitis & Six biopsies, including from the base and the edge of esophageal ulcers & \\
\hline Barrett's esophagus & $\begin{array}{l}\text { In cases with endoscopic evidence of Barrett's esophagus }>1 \mathrm{~cm} \text {, biopsies } \\
\text { should be taken from all visible abnormalities; in addition, random four- } \\
\text { quadrant biopsies should be collected every } 2 \mathrm{~cm} \text { within the Barrett's } \\
\text { segment, starting from the upper end of the gastric folds }\end{array}$ & $\begin{array}{l}\text { Place biopsies from any } \\
\text { abnormalities and from each } \\
\text { level into separate containers }\end{array}$ \\
\hline $\begin{array}{l}\text { Esophageal cancer and early neo- } \\
\text { plasia }\end{array}$ & $\begin{array}{l}\text { At least six biopsies in cases of suspected advanced cancer } \\
\text { Only one to two targeted biopsies for lesions that are potentially } \\
\text { amenable to endoscopic resection }\end{array}$ & \\
\hline Dyspepsia and gastritis & $\begin{array}{l}\text { Two biopsies from the antrum and two from the corpus in patients where } \\
\text { H. pylori is suspected } \\
\text { If staging systems are to be used in patients with atrophy or intestinal } \\
\text { metaplasia (e.g. OLGA, OLGIM), a biopsy in the angle should also be } \\
\text { performed }\end{array}$ & $\begin{array}{l}\text { Place biopsies from antrum } \\
\text { and corpus in separate con- } \\
\text { tainers }\end{array}$ \\
\hline \multicolumn{3}{|l|}{ Gastric polyps } \\
\hline - Fundic gland polyp & Standard biopsies are not required & \\
\hline - Hyperplastic polyp & Biopsy (or resect) if size is $>10 \mathrm{~mm}$ & \\
\hline - Adenoma & Biopsy or, if endoscopically resectable, resect & \\
\hline Gastric cancer and early neoplasia & $\begin{array}{l}\text { At least six biopsies in cases of suspected advanced cancer } \\
\text { Only one to two targeted biopsies for lesions that are potentially } \\
\text { amenable to endoscopic resection } \\
\text { For suspected linitis plastica, at least } 10 \text { bite-on-bite biopsies, targeting } \\
\text { mucosal abnormalities }\end{array}$ & \\
\hline Celiac disease & $\begin{array}{l}\text { At least six biopsies from different locations in the duodenum, including } \\
\text { two samples from the bulb }\end{array}$ & $\begin{array}{l}\text { Biopsies can be collected in } \\
\text { one container }\end{array}$ \\
\hline
\end{tabular}

the sensitivity and specificity of the histologic findings have insufficient diagnostic accuracy and alternative diagnostic methods with higher sensitivity and specificity are available (e.g. reflux monitoring). Biopsies can be considered to exclude alternative diagnoses, if these are suspected based on the patient's symptoms [8-16].

\subsection{Infectious esophagitis}

\section{RECOMMENDATIONS}

ESGE suggests only obtaining biopsies in cases of suspected candida esophagitis if results are expected to have therapeutic consequences. Esophageal biopsies targeted at white plaque-like lesions should be sent for histologic and mycologic analysis when there is treatment resistance.

Weak recommendation, very low quality of evidence.

ESGE recommends obtaining six biopsies, including from the base and edge of the esophageal ulcers, for histologic analysis in patients with suspected viral esophagitis. Strong recommendation, low quality of evidence. 
The most frequent cause of infectious esophagitis is fungal infection by Candida species. When associated with oropharyngeal thrush, upfront empiric antifungal treatment can be considered, as the positive predictive value of oral thrush for candida esophagitis in a patient with dysphagia reaches $77 \%$ [17, 18]. If treatment fails or there is an absence of oropharyngeal lesions, endoscopic inspection and possible sampling of the esophageal mucosa is needed. An endoscopic diagnosis of candida esophagitis may be made by the observation of white or yellowish, plaque-like lesions (so called "cottage-cheese" plaques), and exudates on the esophageal mucosa, which are usually easily removable. White plaque-like lesions on the esophageal mucosa have a positive predictive value for candida esophagitis of $88 \%-90 \%$ [19]. The sensitivity of endoscopic biopsies with histologic assessment ranges from $54 \%$ to $95 \%$ [20-22]. Endoscopic biopsies with fungal culture may be needed in treatment-resistant cases.

In patients with esophageal ulcers, viral esophagitis should be suspected, most commonly caused by herpes simplex virus (HSV 1 or 2) and cytomegalovirus (CMV) [23]. In human immunodeficiency virus (HIV)-infected patients, idiopathic esophageal ulcers must also be considered in the differential diagnosis, as this has therapeutic consequences because these idiopathic esophageal ulcers are best treated with corticosteroids. Whereas HSV typically presents with ulcers in immunocompromised patients, in elderly patients it may present with vesicles and "volcano-shaped" mucosal structures. Conflicting data on the recommended number of endoscopic biopsies is possibly explained by the need to perform biopsies on the ulcer edge to observe the cytopathogenic effect of HSV and on the ulcer base for CMV [24]. Biopsies have a sensitivity of $68 \%-100 \%$ for HSV and $90 \%-100 \%$ for CMV [24-33].

Viral culture, although highly specific [24], is not available in most centers [34]. The only prospective study in the field did not observe an added diagnostic value of viral culture over routine histologic evaluation with immunohistochemical staining for CMV and HSV antigens [24]. Furthermore, the use of immunohistochemistry has not been consistently shown to improve detection of HSV and CMV [35]. Finally, routine hematoxylin and eosin staining is accurate for the diagnosis of most cases of viral esophagitis; immunohistochemical staining can be of help in selected cases.

Besides candida, HSV, and CMV esophagitis, other rare causes of infectious diagnoses should be kept in mind in the presence of esophageal ulceration, such as Epstein-Barr virus, Leishmania, and tuberculous esophagitis.

\subsection{Barrett's esophagus}

\section{RECOMMENDATION}

ESGE recommends that, in patients with endoscopic evidence of Barrett's esophagus of $>1 \mathrm{~cm}$, biopsy samples should be taken from all visible mucosal abnormalities. In addition, random four-quadrant biopsies should be collected every $2 \mathrm{~cm}$ within the Barrett's segment, starting from the upper end of the gastric folds. Biopsies from each level should be collected in and presented to the pathologist in a separate container.

Strong recommendation, high quality of evidence.

For evidence, please refer to the existing ESGE position statement [36]. No new evidence is available on this statement.

\subsection{Esophageal cancer and early neoplasia}

\section{RECOMMENDATIONS}

ESGE recommends at least six biopsies are taken in cases of suspected advanced esophageal cancer.

Strong recommendation, moderate quality of evidence.

ESGE recommends taking only one to two targeted biopsies for lesions that are potentially amenable to endoscopic resection (Paris classification $0-\mathrm{I}, 0-\mathrm{II}$ ) in order to confirm the diagnosis and not compromise subsequent endoscopic resection.

Strong recommendation, low quality of evidence.

High definition white-light upper gastrointestinal endoscopy using standard or virtual chromoendoscopy with biopsy is the recommended diagnostic modality for all suspected cases of esophageal cancer. Any lesion suspicious for cancer should be sampled and sent to pathology in a separate container. In cases with potentially malignant esophageal stenosis, an ultrathin endoscope should be used to complete the esophagogastroduodenoscopy and obtain tissue samples from inside the stenosis. The sensitivity of endoscopic forceps biopsies for esophageal cancer ranges from $92 \%$ for a single biopsy to $100 \%$ for six biopsies [37-39]. There is no role for cytology [40].

Early esophageal neoplasia is best staged and treated by endoscopic resection. Furthermore, extensive biopsy sampling can jeopardize subsequent endoscopic resection by inducing submucosal fibrosis. Therefore, where there is a suspected neoplastic esophageal lesion that is potentially amenable to endoscopic resection (Paris type 0 -I or 0 -II), one to two endoscopic biopsies, targeted on the most suspicious parts of the lesion, should be taken to document the presence of dysplasia or neoplasia.

Conversely, where a lesion is not amenable to endoscopic resection (esophageal stenosis, Paris type $\geq 0$-III), at least six endoscopic biopsies should be obtained [41]. > Fig. 1 illustrates examples of early and advanced esophageal neoplasia. 


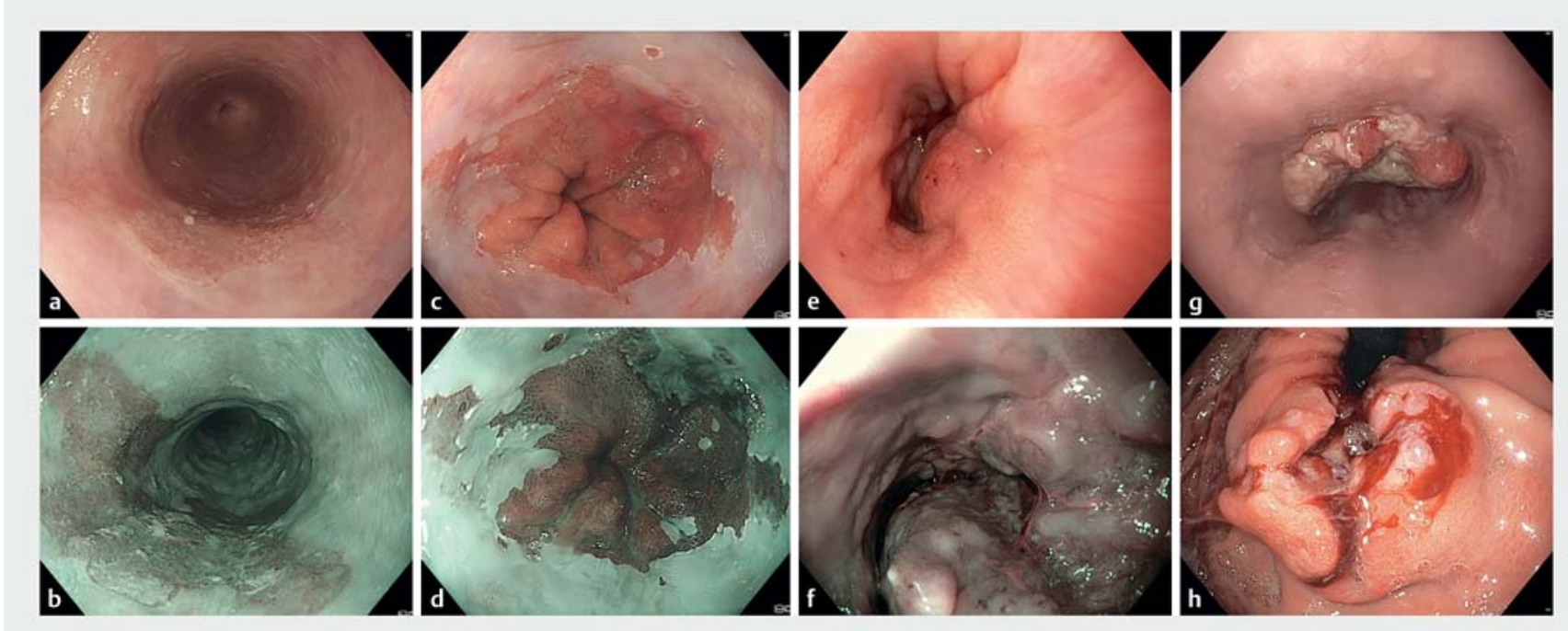

- Fig. 1 Endoscopic images of esophageal neoplasia showing: a, b early Paris type 0 -IIb squamous cell cancer from the 4-10 o'clock position on: a white-light endoscopy (WLE); b narrow-band imaging (NBI); c, d early Paris type 0-Ila-IIb adenocarcinoma from the 12-4 o'clock position in a short segment Barrett's esophagus on: $\mathbf{c}$ WLE; $\mathbf{d}$ NBI; e, $\mathbf{f}$ advanced esophageal squamous cell cancer on: e WLE; $\mathbf{f}$ NBI; $\mathbf{g}$, $\mathbf{h}$ advanced distal esophageal adenocarcinoma on: $\mathbf{g}$ antegrade view; $\boldsymbol{h}$ retroflexed view.

\subsection{Dyspepsia and gastritis}

\section{RECOMMENDATIONS}

ESGE recommends obtaining two biopsies from the antrum and two from the corpus in patients with suspected Helicobacter pylori infection and for gastritis staging. Strong recommendation, low quality of evidence.

ESGE recommends placing biopsies from the antrum and corpus into separate containers.

Strong recommendation, high quality of evidence.

Helicobacter pylori is a potentially curable cause of dyspepsia, peptic ulcer disease, and gastric adenocarcinoma or mucosaassociated lymphoid tissue (MALT) lymphoma. The management of $\mathrm{H}$. pylori infection was consecutively summarized in the Maastricht/Florence Consensus Report [42]. The indications for endoscopy-based diagnosis vary according to the a priori chance of malignancy or previous treatments, and are beyond the scope of this guideline.

During such procedures, biopsies should be performed in the antrum and corpus. The need to assess both compartments is drawn from indirect evidence of the patchy distribution in the corpus in surgical specimens and that, with age and expansion of pyloric glands, a distal to proximal gastric spread of $H$. pylori occurs [43-45]. Moreover, according to the management of precancerous conditions and lesions in the stomach (MAPS) guidelines, biopsies should be taken with the purpose of staging atrophy/intestinal metaplasia as this will affect the allocation to different surveillance strategies [46]. Different containers should be used for specimens from the antrum and the corpus. A single container may be enough according to local expertise, both of the pathologists and the endoscopists, after proper training and if the endoscopic risk of extensive intestinal metaplasia is diminutive or during surveillance of individuals with known atrophic status [47]. If staging systems are to be used in patients with atrophy or intestinal metaplasia (e.g. OLGA, OLGIM), a biopsy in the angle should also be performed as described extensively in the ESGE MAPS-II guideline.

This evidence refers to the existing ESGE guideline [46]. No new evidence is available on this statement.

\subsection{Gastric polyps}

Gastric polyps are commonly encountered lesions during routine endoscopy. They are usually asymptomatic and nonneoplastic, and may be found sporadically or in association with polyposis syndromes. Some gastric polyps may have malignant potential. Gastric polyps can be mainly distinguished as fundic gland polyps (FGPs), hyperplastic polyps, and adenomatous polyps and can mostly be classified endoscopically based on their typical endoscopic appearance ( $>$ Fig. 2). Biopsies for classification are therefore superfluous but may be considered if in doubt and if the outcome has clinical relevance. For an endoscopically resectable polyp with the need for a histologic diagnosis, resection is preferred over biopsies, because biopsies may underestimate the neoplastic progression risk owing to sampling error. 

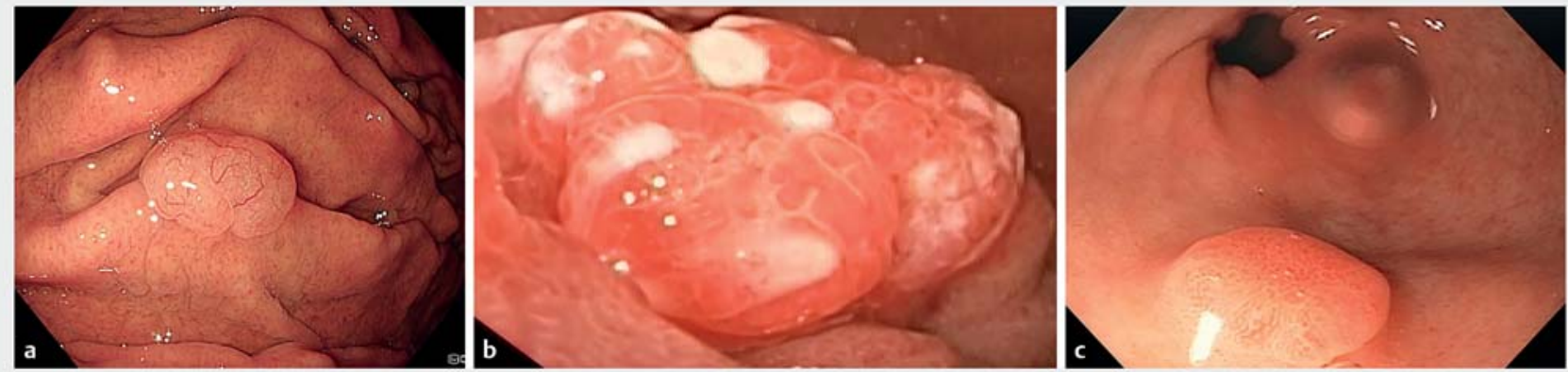

- Fig. 2 Endoscopic images of the various types of gastric polyps: a fundic gland polyp; $\mathbf{b}$ hyperplastic polyp; c gastric adenoma (source for Fig. 2c: Dr. S. Mühldorfer).

\subsubsection{Fundic gland polyps}

\section{RECOMMENDATION}

ESGE does not recommend standard biopsies of fundic gland polyps.

Strong recommendation, low quality of evidence.

FGPs are the most frequently encountered gastric polyps. They are usually found in patients with chronic PPI use or in association with polyposis syndromes. A diagnosis of FGPs is often made based on the endoscopic appearance. FGPs are usually present in the fundus and gastric body. They are characterized by their small size $(<10 \mathrm{~mm})$ and luminous, glossy appearance ( $\triangleright$ Fig. 2 a).

Neoplastic features are rarely found in FGPs, with the exception of FGPs on the background of a polyposis syndrome. Case series of FGPs reveal low grade dysplasia (LGD) in $<1 \%$ of FPGs $[48,49]$. There have been limited case reports published on the occurrence of high grade dysplasia (HGD) and gastric carcinoma in FGPs [50-52]. Large (>10 mm) FGPs seem to have a slightly higher risk for the presence of dysplasia or focal cancer compared with small (<10 mm) FGPs [53]. The risk of malignant progression of sporadic or PPI-associated FGPs is very low. In cases where FGPs have atypical features, size of $>1 \mathrm{~cm}$, antral location, ulceration, or unusual appearance, biopsies of the FGP can be considered.

\subsubsection{Hyperplastic polyps}

\section{RECOMMENDATION}

ESGE recommends taking biopsies from (or resection of) hyperplastic polyps of $>10 \mathrm{~mm}$.

Strong recommendation, low quality of evidence.

Gastric hyperplastic (hyperplasiogenic) polyps are a result of chronic inflammation of the gastric mucosa, mainly due to $H$. pylori infection or autoimmune gastritis. They appear as soli- tary, sessile or pedunculated lesions with an eroded surface and are mainly located in the antrum ( $\mathbf{F i g . 2 b ) . ~ M u l t i p l e ~}$ hyperplastic polyps can also be present, usually in association with a hereditary disorder [54].

In the literature, large variations in neoplastic progression rates of gastric hyperplastic polyps are documented. Focal carcinoma can be present in $0 \%-8 \%$ of hyperplastic polyps [5559]. The presence of a hyperplastic polyp appears to be associated with an increased risk, up to $8.5 \%$, of gastric cancer development in the surrounding gastric mucosa $[53,60]$.

Large (>10 mm) hyperplastic polyps are more at risk of harboring dysplastic foci compared with small (<10 mm) hyperplastic polyps $[59,61]$. Recurrence rates after the resection of large hyperplastic polyps are high, up to $55 \%$ has been described $[61,62]$.

\subsubsection{Adenomas}

\section{RECOMMENDATION}

ESGE recommends biopsies from or, if endoscopically resectable, resection of gastric adenomas.

Strong recommendation, moderate quality of evidence.

Gastric adenomas can be found sporadically or in association with familial polyposis syndrome. They appear as solitary, delineated lesions that are often eroded ( $\triangleright$ Fig. $\mathbf{2 c}$ ). Adenomas can be distinguished as tubular, villous, or tubulovillous adenomas. Histologically, their differentiation can be intestinal or gastric. Gastric differentiation includes pyloric gland adenomas, rare foveolar adenomas, and even more rare oxyntic gland adenomas. They may occur anywhere in the stomach, although they are frequently encountered in the antrum.

Adenomas are associated with atrophic gastritis and gastric cancer development in the surrounding gastric mucosa [6365]. According to the literature, foci of carcinoma are present in up to $38 \%$ of adenomas [65-67]. Gastric adenomas are precancerous lesions with a risk of neoplastic progression. 

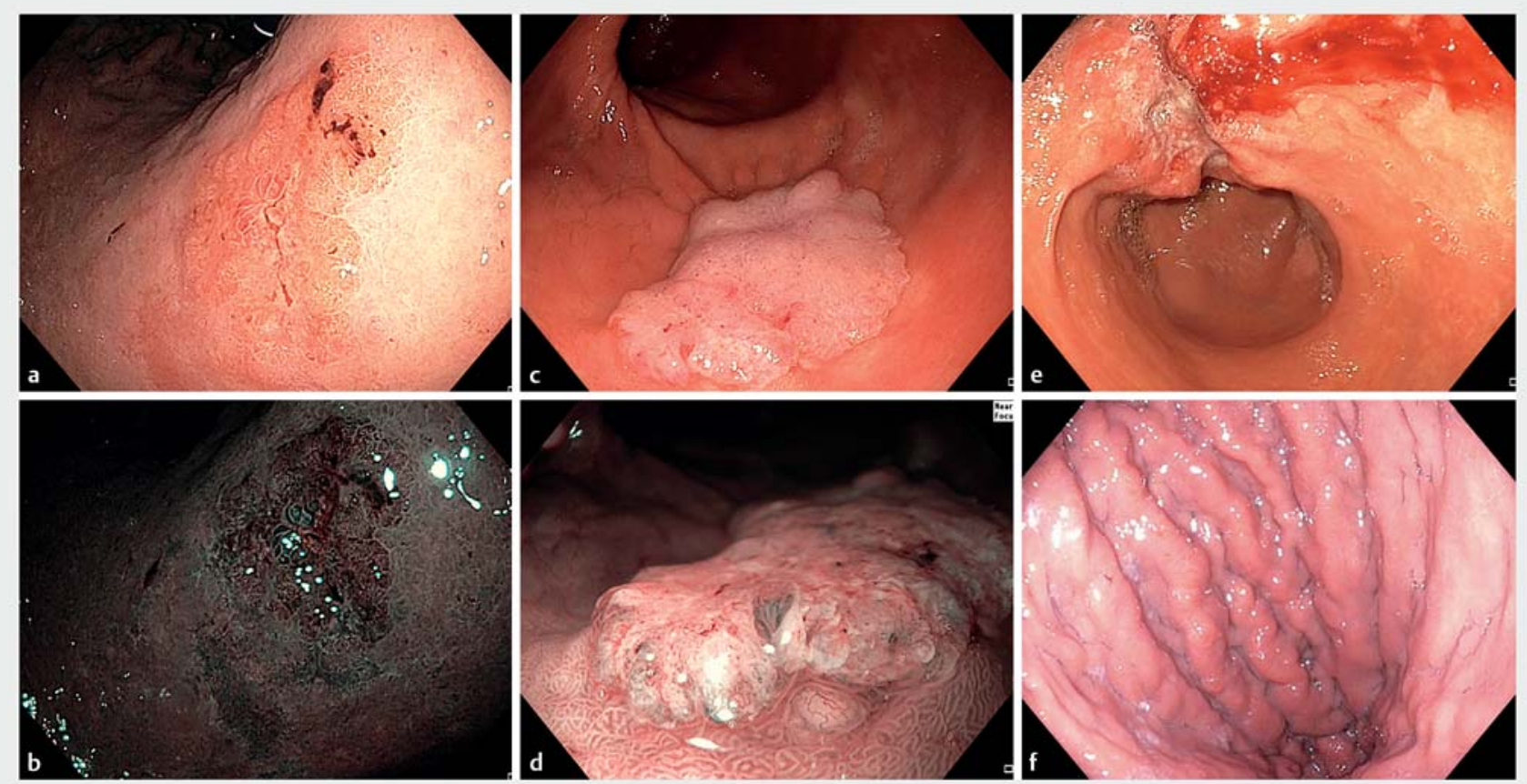

Fig. 3 Endoscopic images of gastric neoplasia showing: a, b early Paris type 0-IIb mucosal gastric cancer on: a white-light endoscopy (WLE); b narrow-band imaging (NBI); c, d early Paris type 0 -Ila submucosal gastric cancer on: c WLE; $\mathbf{d}$ near focus with NBI; e advanced ulcerative gastric cancer (Borrmann type III); f linitis plastica (Borrmann type IV).

\subsection{Gastric cancer}

\section{RECOMMENDATIONS}

ESGE recommends at least six biopsies in cases of suspected advanced gastric cancer.

Strong recommendation, moderate quality of evidence.

ESGE recommends taking only one to two targeted biopsies for lesions that are potentially amenable to endoscopic resection (Paris classification 0 -II) to confirm the diagnosis and allow subsequent endoscopic resection. Strong recommendation, low quality of evidence.

High definition upper gastrointestinal endoscopy with biopsy is the recommended diagnostic modality for all suspected cases of gastric neoplasia. Any lesion suspicious of neoplasia should be sampled and sent to pathology in a separate container.

Early gastric neoplasia is best staged and treated by endoscopic resection. Furthermore, extensive biopsy sampling can jeopardize subsequent endoscopic resection by inducing scarring and submucosal fibrosis. Therefore, for suspected neoplastic gastric lesions that are potentially amenable to endoscopic resection, the number of endoscopic biopsies should be limited. One large retrospective study showed that two endoscopic biopsies yielded a $92.5 \%$ diagnostic accuracy for early gastric neoplasia [68]. Therefore, two biopsies targeted on the most suspicious parts of the lesion should be taken to document the presence of dysplasia or neoplasia. Conversely, for lesions not amenable to endoscopic resection (Paris classification 0 -I or 0 -III, ulcerated lesions $>3 \mathrm{~cm}$ ) where surgery or oncologic treatments will be requested, although three endoscopic biopsies will yield a $98.3 \%$ sensitivity, at least six endoscopic biopsies should be obtained, in order to assess the expression of potential biomarkers, such as Her2neu [41, 69]. > Fig. 3 illustrates examples of early and advanced gastric neoplasia.

\section{RECOMMENDATIONS}

ESGE suggests obtaining at least 10 bite-on-bite biopsies in cases of suspected gastric linitis plastica, targeting mucosal abnormalities.

Weak recommendation, low quality of evidence.

ESGE suggests that, where there are negative biopsies and a persisting suspicion of gastric linitis plastica, endoscopy with more extensive biopsies can be repeated. Endoscopic ultrasound (EUS) may be used to target biopsies or fine-needle aspiration/biopsy (FNA/B) of the most affected part of the stomach.

Weak recommendation, low quality of evidence.

Obtaining a histologic diagnosis of gastric linitis plastica (diffuse gastric cancer) can be challenging because tumor cells 
are diffusely spread in the gastric submucosa and stroma, and the mucosa is often normal. Where there is a radiologic or endoscopic suspicion of linitis plastica (presence of large folds, gastric stenosis, circumferential thickening of at least one segment, lack of stomach distensibility, or thickening of the third hyperechogenic layer on endoscopic ultrasound [EUS]) [70], it is advisable to obtain at least 10 bite-on-bite biopsies of the areas that appear most abnormal $[71,72]$. If biopsies are negative, these can be repeated to obtain more tissue. As for $C D H 1$ patients, the Cambridge protocol could be used [71,72].

In addition, EUS can be used to identify the most affected area of the stomach and to guide target biopsies or fine-needle aspiration/biopsy (FNA/B). FNA of the gastric wall or suspicious lymph nodes has been reported to be helpful in some cases, although data are scarce [73-75]. Other possibilities for obtaining tissue samples from the submucosa, such as submucosal tunneling or prior endoscopic resection of overlying normal mucosa, have been described but evidence on the efficacy and safety of these techniques is very limited [76].

\subsection{Celiac disease}

\section{RECOMMENDATION}

ESGE recommends at least six biopsies from different locations in the duodenum, including two samples from the duodenal bulb, in patients with a suspicion of celiac disease. Biopsies can be collected in the same container. Strong recommendation, high quality of evidence.

Celiac disease is characterized by typical histologic changes. Mucosal changes appear mostly in the proximal part of the small intestine and may be patchy. Therefore, mucosal changes may be missed if insufficient biopsies are obtained. Studies have demonstrated that in patients with ultrashort celiac disease, pathology may be confined to the duodenal bulb [77]. Including biopsies from the bulb increases the diagnostic yield of endoscopic biopsies for the diagnosis of celiac disease. ESGE adheres to the advice from the World Gastroenterology Organisation and American College of Gastroenterology, namely to obtain at least six biopsies from different sites in the small bowel, including two biopsies from the duodenal bulb, in patients with a suspicion of celiac disease based on endoscopy or serology [78-83].

This represents agreement between merged guidelines [78, 79]. No new evidence is available on this statement.

\section{Hepatopancreatobiliary tract}

\subsection{Liver}

Tissue sampling is often required for solid liver lesions or parenchymal liver disease. For both indications, the method of choice is a percutaneous approach, which has been well established and provides core samples for histologic diagnosis. EUSguided biopsy may be considered in specific situations, such as anatomical issues, failure of percutaneous biopsy, or concomi- tant indications for EUS. For example, EUS-guided liver biopsy has recently been increasingly used for patients in whom diagnostic EUS is being performed to exclude extrahepatic biliary obstruction [84], evaluate esophageal varices, or perform portal pressure gradient measurement.

\subsubsection{Liver tumors}

\section{RECOMMENDATION}

ESGE suggests performing EUS-guided sampling of solid liver masses suspicious for malignancy, if the pathologic result will affect patient management and (i) the lesion is poorly accessible/not detected at percutaneous imaging, or (ii) a sample obtained via the percutaneous route has repeatedly yielded an inconclusive result.

Weak recommendation, low quality of evidence.

For solid liver masses that are suspicious for malignancy or metastases, histologic tissue sampling can be necessary to decide on further patient management. Generally, tissue sampling of these lesions is performed percutaneously. However, recently, there have been reports on the use of EUS-FNA to sample solid liver masses suspicious for malignancy, with high specimen adequacy and diagnostic accuracy [85]. Although this indication for EUS-FNA is relatively new and not yet clearly defined, one may consider it in cases where lesions are poorly accessible or not detected by percutaneous imaging, or if percutaneous sampling has repeatedly yielded an inconclusive result.

\subsubsection{Parenchymal liver disease}

\section{RECOMMENDATION}

ESGE suggests, where EUS-guided sampling is indicated, the use of larger caliber needles (19G FNA or FNB needles) in cases of suspected parenchymal liver disease. Weak recommendation, low quality evidence.

EUS-guided liver biopsy has been increasingly used, especially in patients in whom diagnostic EUS is being performed to exclude extrahepatic biliary obstruction. Newer indications may include patients with unknown liver disease undergoing endoscopic evaluation of esophageal varices or portal pressure gradient measurement. Generally, liver biopsy requires histologic evaluation of a specimen of a minimum size and number of portal tracts, making proper needle selection important. A number of studies have evaluated and compared the use of differently sized FNA needles and FNB. Samples adequate for histopathologic evaluation were acquired more often with 19 G FNA needles or FNB, compared with smaller sized needles. Factors such as the technique of biopsy may contribute to the tissue yield rather than the needle itself [86-96]. 


\subsection{Pancreatic solid masses}

\section{RECOMMENDATIONS}

ESGE recommends FNA and FNB needles equally for sampling of solid pancreatic masses.

Strong recommendation, high quality evidence.

ESGE suggests using newer generation FNB needles (with forward-facing bevels, fork tip, or crown tip) when the aim is to obtain core tissue (e.g. neuroendocrine neoplasia, need for tumor genotype profiling) and when rapid onsite evaluation (ROSE) is not available. Weak recommendation, moderate quality evidence.

Since the 2017 ESGE guideline on EUS-guided sampling [97], a number of randomized trials and six meta-analyses comparing FNA and FNB sampling in pancreatic masses have been published. These publications support the recommendation from 2017 that FNA and FNB are recommended equally for the sampling of pancreatic masses [98-114]. Overall, the diagnostic yield does not differ between FNA and FNB needles [110, 113], but some studies indicate that the sample adequacy for histologic evaluation is higher when using FNB compared with FNA needles $[99,100,111,112]$. There is some evidence suggesting that the use of FNB results in more tissue and higher diagnostic accuracy with fewer needle passes than FNA [98-101, $104-106,109,111,114]$, which may be relevant in cases where core tissue is required for diagnosis or genetic profiling, or when rapid onsite evaluation (ROSE) is not available. The handling of specimens is addressed below. Technical aspects of EUSguided tissue sampling are described in the 2017 ESGE clinical guideline [97].

\subsection{Bile ducts}

The majority of biliary strictures are malignant (70\%-80\%), with a limited number of causes (i. e. cholangiocarcinoma, pancreatic cancer, gall bladder carcinoma, metastatic disease, or lymphoma). A benign etiology may also be found in 20\%-30\%, with a much broader differential diagnosis (e.g. IgG4 disease, primary sclerosing cholangitis, infection, post-trauma or postsurgery, and vasculitis, among others) [115]. Early diagnosis of biliary strictures is important for achieving optimal patient outcomes and avoiding unnecessary surgical procedures. The etiology of most biliary strictures can be diagnosed after a basic work-up including transabdominal imaging, endoscopic retrograde cholangiopancreatography (ERCP) with standard transpapillary tissue sampling, or EUS-FNA/B in cases of suspected pancreatic malignancy. Those cases in which this basic workup is non-diagnostic are referred to as indeterminate biliary strictures.

\subsubsection{Indeterminate biliary strictures}

\section{RECOMMENDATIONS}

ESGE suggests performing peroral cholangioscopy (POC) and/or EUS-guided tissue acquisition in indeterminate biliary strictures. For proximal and intrinsic strictures, POC is preferred. For distal and extrinsic strictures, EUSguided sampling is preferred, with POC where this is not diagnostic.

Weak recommendation, low quality evidence.

ESGE suggests that performing POC with visually guided biopsies provides the highest chance of confirming malignancy.

Weak recommendation, moderate quality evidence.

Studies have demonstrated a high sensitivity (75\%-94\%) and diagnostic accuracy (79\%-94\%) for EUS-guided sampling in indeterminate strictures, which is much higher than the sensitivity (49\%-60\%) and diagnostic accuracy (60\%-61\%) for ERCP-guided brush cytology [116-118].

For peroral cholangioscopy (POC), meta-analyses have reported a sensitivity of $72 \%-94 \%$ and a specificity of $87 \%-99 \%$ for cholangioscopy-guided biopsies in indeterminate strictures [119-123]. The sensitivity and accuracy of POC were proved to be higher than those of ERCP in indeterminate strictures in a randomized study [124]. It suggested that POC may be preferable for proximal and intrinsic strictures, whereas EUS-guided tissue sampling may be preferable for distal and extrinsic strictures $[124,125]$.

\section{Miscellaneous}

\subsection{Biopsy handling, technical aspects}

\section{RECOMMENDATIONS}

ESGE suggests that mucosal biopsy specimens are released into labelled containers containing adequate amounts of tissue fixation fluid ( $10 \%$ buffered formalin). Weak recommendation, low quality of evidence.

ESGE recommends obtaining biopsies for microbial testing or fresh biopsy material first, before the biopsy forceps has come into contact with any tissue fixation fluid.

Strong recommendation, low quality of evidence.

ESGE suggests obtaining possible non-neoplastic biopsies before sampling suspected malignant lesions to prevent intraluminal spread of malignant disease.

Weak recommendation, low quality of evidence. 
Proper biopsy handling is of paramount importance in maximizing clinical return and maintaining endoscopy quality standards. Mucosal biopsy specimens should be gently released into labelled biopsy containers containing adequate amounts of tissue fixation fluid. Fixation stops cellular autolysis and prepares tissues for embedding and sectioning. Although a range of fixatives are available for specific downstream purposes (for example glutaraldehyde for electron microscopy studies in cases of pediatric failure to thrive), in general $10 \%$ buffered formalin is the fixative of choice for mucosal biopsies. This is compatible with point-of-care molecular (panel) sequencing tests and the global standard for antigen retrieval in immunohistochemical studies. Comparative studies examining other fixatives in standard endoscopy practice are not available.

If tissue material for microbial testing is required, this should be secured first. If fresh biopsy material is required, for example for molecular testing or enzymatic studies, this should not be obtained with biopsy forceps that have come into contact with any tissue fixation fluid. Studies have suggested that, in some cases, biopsy instrumentation may facilitate intraluminal spread of malignant disease, indicating that, where possible, non-neoplastic biopsies should be secured before any suspected malignant lesions are sampled.

Direct communication with histopathology staff is encouraged to improve quality standards and ensure that specimens are handled in line with institutional practices. For example, work-up of endoluminal resection specimens and essential pathology requisition details are best discussed within the context of multidisciplinary team meetings and benefit greatly from alignment between endoscopy and histopathology staff [126, 127].

\subsection{Type of biopsy forceps}

\section{RECOMMENDATION}

ESGE suggests the use of a standard cold biopsy forceps, because there is too little benefit in terms of histopathologic outcome to recommend the use of a jumbo biopsy forceps.

Weak recommendation, moderate quality of evidence.

Various studies have examined the impact of biopsy forceps design on tissue adequacy in a pathologist-blinded fashion. Different types of biopsy forceps are available, with serrated jaws, oval beaks, different jaw sizes, and with a spike to be able to contain two biopsies within the cups of the forceps. Jumbo biopsy forceps sample about three times the surface area compared with standard cold biopsy forceps, but importantly do not consistently provide deeper specimens. Despite variations in the designs of different biopsy forceps and their claimed benefits, studies agree that there are no reproducible differences in tissue adequacy or clinically relevant histopathologic outcome [128-131].

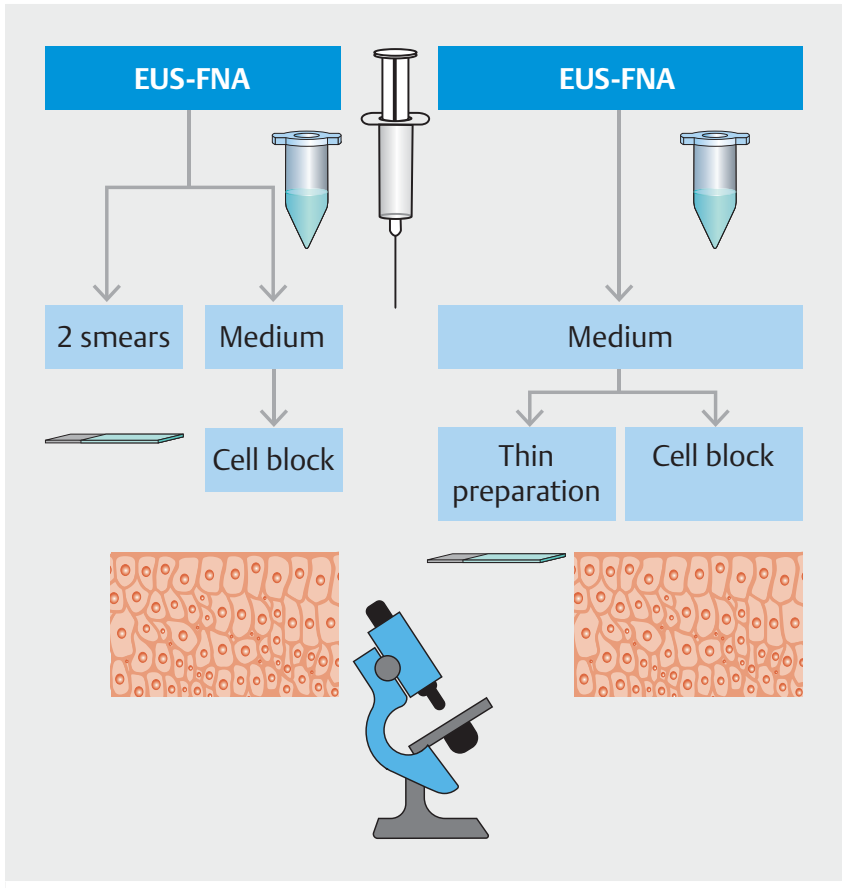

- Fig. 4 Diagram of the preparation of tissue specimens obtained by endoscopic ultrasound-guided fine-needle aspiration (EUS-FNA) into smears and a cell block, or alternatively into liquid-based cytology with a thin preparation as the first step and a cell block as the second step.

\subsection{Preparation of EUS-FNA material}

\section{RECOMMENDATION}

ESGE suggests dividing EUS-FNA material into smears (two per pass) and liquid-based cytology (LBC), or the whole of the EUS-FNA material can be processed as LBC, depending on local experience.

Weak recommendation, low quality evidence.

Adequate preparation of FNA samples and dedicated training of cytotechnologists and pathologists are the prerequisites for achieving optimal results. Cytologic tissue can be evaluated using smears or liquid-based cytology (LBC), or both. LBC material can be further processed as thin preparations and/or cell blocks.

Depending on the practical experience of the involved pathology personnel, EUS-FNA material could be divided into smears (two per pass) and a cell block for additional evaluation. Alternatively, the whole of the EUS-FNA material can be processed as LBC, with a thin preparation as the first step and a cell block as the second step ( $\triangleright$ Fig. 4) [132-138].

\section{Disclaimer}

The legal disclaimer for ESGE guidelines [139] applies to this Guideline. 


\section{Acknowledgments}

The authors are grateful to Dr. Cesare Hassan, Nuovo Regina Margherita Hospital, Rome, Italy, and Professor Klaus Mönkemüller, Department of Gastroenterology, Helios Frankenwaldklinik Kronach, Germany for their review of the manuscript.

\section{Competing interests}

M. Barret has received consultancy fees from Medtronic (2018 to present) and Pentax (2019 to present). R. Bisschops has received consultancy and speaker's fees from Fujifilm, Pentax, Medtronic (all 2015 to present), and Norgine (2016 to present), consultancy fees from Boston Scientific, Cook (both 2015 to present), CDx Diagnostics (2017 to present), and GI Supply (2018 to present), and speaker's fees from Medivators (2017 to 2018) and Ipsen (2020 to present); his department has received research grants from Fujifilm, Pentax (both 2015 to present), Cook (2016 to 2019), and Medtronic (2018 to present). M. Dinis Ribeiro is co-editor-in-chief of Endoscopy; his department has received a research grant from Fujifilm (2020 to present) and an educational grant from Olympus (2020 to present). M. lacucci has received research grant support from Pentax (2016 to present), Olympus (2018 to 2020), and Fujifilm (2019 to present). M.C.W. Spaander has received research support from Boston Scientific (2013 to present) and Cook Medical (2009 to 2013). J.E. van Hooft has received lecture fees from Medtronic (2014, 2015, and 2019) and Cook Medical (2019), and consultancy fees from Boston Scientific (2014 to 2017) and Olympus (2021); her department has received research grants from Abbot (2014 to 2017) and Cook Medical (2014 to 2019). K. Biermann, L. Czakó, K.B. Gecse, G. de Hertogh, T. Hucl, M. Jansen, R.E. Pouw, M. Rutter, E. Savarino, P.T. Schmidt, and $M$. Vieth declare that they have no conflict of interest.

\section{References}

[1] GRADE Working Group. Grading quality of evidence and strength of recommendations. BMJ 2004; 328: 1490

[2] Dumonceau JM, Hassan C, Riphaus A et al. European Society of Gastrointestinal Endoscopy (ESGE) Guideline Development Policy. Endoscopy 2012; 44: 626-629

[3] Nielsen JA, Lager DJ, Lewin M et al. The optimal number of biopsy fragments to establish a morphologic diagnosis of eosinophilic esophagitis. Am J Gastroenterol 2014; 109: 515-520

[4] Shoda T, Wen T, Aceves SS et al. Eosinophilic oesophagitis endotype classification by molecular, clinical, and histopathological analyses: a cross-sectional study. Lancet Gastroenterol Hepatol 2018; 3: 477488

[5] Dellon ES, Speck O, Woodward K et al. Markers of eosinophilic inflammation for diagnosis of eosinophilic esophagitis and proton pump inhibitor-responsive esophageal eosinophilia: a prospective study. Clin Gastroenterol Hepatol 2014; 12: 2015-2022

[6] Lucendo AJ, Molina-Infante J, Arias Á et al. Guidelines on eosinophilic esophagitis: evidence-based statements and recommendations for diagnosis and management in children and adults. United European Gastroenterol J 2017; 5: 335-358

[7] Yantiss RK, Odze RD. Optimal approach to obtaining mucosal biopsies for assessment of inflammatory disorders of the gastrointestinal tract. Am J Gastroenterol 2009; 104: 774-783

[8] Narayani RI, Burton MP, Young GS. Utility of esophageal biopsy in the diagnosis of nonerosive reflux disease. Dis Esophagus 2003; 16: 187-192
[9] Schindlbeck NE, Wiebecke B, Klauser AG et al. Diagnostic value of histology in non-erosive gastro-oesophageal reflux disease. Gut 1996; 39: 151-154

[10] Pinto D, Plieschnegger W, Schneider NI et al. Carditis: a relevant marker of gastroesophageal reflux disease. Data from a prospective central European multicenter study on histological and endoscopic diagnosis of esophagitis (histoGERD Trial). Dis Esophagus 2019: doi:10.1093/dote/doy073

[11] Zhou LY, Wang Y, Lu J] et al. Accuracy of diagnosing gastroesophageal reflux disease by GerdQ, esophageal impedance monitoring and histology. J Dig Dis 2014; 15: 230-238

[12] Zentilin P, Savarino V, Mastracci L et al. Reassessment of the diagnostic value of histology in patients with GERD, using multiple biopsy sites and an appropriate control group. Am J Gastroenterol 2005; 100: 2299-2306

[13] Schneider NI, Plieschnegger W, Geppert M et al. Validation study of the Esohisto consensus guidelines for the recognition of microscopic esophagitis (histoGERD Trial). Hum Pathol 2014; 45: 994-1002

[14] Gyawali C, Kahrilas PJ, Savarino E et al. Modern diagnosis of GERD: the Lyon consensus. Gut 2018; 67: 1351-1362

[15] Madan K, Ahuja V, Gupta SD et al. Impact of 24-h esophageal pH monitoring on the diagnosis of gastroesophageal reflux disease: defining the gold standard. J Gastroenterol Hepatol 2005; 20: 30-37

[16] Savarino E, Zentilin P, Mastracci L et al. Microscopic esophagitis distinguishes patients with non-erosive reflux disease from those with functional heartburn. J Gastroenterol 2013; 48: 473-482

[17] Antinori A, Antinori A, Ammassari A et al. Presumptive clinical criteria versus endoscopy in the diagnosis of Candida esophagitis at various HIV-1 disease stages. Endoscopy 1995; 27: 371-376

[18] Wilcox CM, Alexander LN, Clark WS et al. Fluconazole compared with endoscopy for human immunodeficiency virus-infected patients with esophageal symptoms. Gastroenterology 1996; 110: 18031809

[19] Redah D, Konutse AY, Agbo K et al. Is endoscopic diagnosis of Candida albicans esophagitis reliable? Correlations with pathology and mycology. Gastroenterol Clin Biol 2001; 25: 161-163

[20] Muniraj F, Siddaraju N, Sistla SC. Role of brush cytology in the diagnosis of neoplastic and non-neoplastic upper gastrointestinal lesions. Cytopathology 2016; 27: 407-417

[21] Geisinger KR. Endoscopic biopsies and cytologic brushings of the esophagus are diagnostically complementary. Am J Clin Pathol 1995; 103: 295-299

[22] Bonacini M, Young T, Laine L. The causes of esophageal symptoms in human immunodeficiency virus infection. A prospective study of 110 patients. Arch Intern Med 1991; 151: 1567-1572

[23] Ramanathan J, Rammouni M, Baran J Jr et al. Herpes simplex virus esophagitis in the immunocompetent host: an overview. Am J Gastroenterol 2000; 95: 2171-2176

[24] Wilcox CM, Rodgers W, Lazenby A. Prospective comparison of brush cytology, viral culture, and histology for the diagnosis of ulcerative esophagitis in AIDS. Clin Gastroenterol Hepatol 2004; 2: 564-567

[25] Theise ND, Rotterdam H, Dieterich D. Cytomegalovirus esophagitis in AIDS: diagnosis by endoscopic biopsy. Am J Gastroenterol 1991; 86: $1123-1126$

[26] Wilcox CM, Diehl DL, Cello JP et al. Cytomegalovirus esophagitis in patients with AIDS. A clinical, endoscopic, and pathologic correlation. Ann Intern Med 1990; 113: 589-593

[27] Bernard S, Germi R, Lupo J et al. Symptomatic cytomegalovirus gastrointestinal infection with positive quantitative real-time PCR findings in apparently immunocompetent patients: a case series. Clin Microbiol Infect 2015; 21: 1121 
[28] Wheeler RR, Peacock JE Jr, Cruz JM et al. Esophagitis in the immunocompromised host: role of esophagoscopy in diagnosis. Rev Infect Dis 1987; 9: 88-96

[29] Jazeron JF, Barbe C, Frobert E et al. Virological diagnosis of herpes simplex virus 1 esophagitis by quantitative real-time PCR assay. J Clin Microbiol 2012; 50: 948-952

[30] McBane RD, Gross JB Jr. Herpes esophagitis: clinical syndrome, endoscopic appearance, and diagnosis in 23 patients. Gastrointest Endosc 1991; 37: 600-603

[31] Agha FP, Lee HH, Nostrant TT. Herpetic esophagitis: a diagnostic challenge in immunocompromised patients. Am J Gastroenterol 1986; 81: 246-253

[32] Généreau T, Lortholary O, Bouchaud O et al. Herpes simplex esophagitis in patients with AIDS: report of 34 cases. The Cooperative Study Group on Herpetic Esophagitis in HIV Infection. Clin Infect Dis 1996; 22: 926-931

[33] Qumseya B, Saeian K, Massey BT. Endoscopic biopsy for cytomegalovirus in symptomatic immunocompromised patients has low yield in the absence of mucosal lesions. Gastrointest Endosc 2009; 69: AB206

[34] Canalejo E, García Durán F, Cabello N et al. Herpes esophagitis in healthy adults and adolescents: report of 3 cases and review of the literature. Medicine (Baltimore) 2010; 89: 204-210

[35] Mönkemüller KE, Bussian AH, Lazenby A] et al. Special histologic stains are rarely beneficial for the evaluation of HIV-related gastrointestinal infections. Am J Clin Pathol 2000; 114: 387-394

[36] Weusten B, Bisschops R, Coron E et al. Endoscopic management of Barrett's esophagus: European Society of Gastrointestinal Endoscopy (ESGE) position statement. Endoscopy 2017; 49: 191-198

[37] Lal N, Bhasin DK, Malik AK et al. Optimal number of biopsy specimens in the diagnosis of carcinoma of the oesophagus. Gut 1992; 33: 724-726

[38] Graham DY, Schwartz JT, Cain GD et al. Prospective evaluation of biopsy number in the diagnosis of esophageal and gastric carcinoma. Gastroenterology 1982; 82: 228-231

[39] Nagai K, Ishihara R, Ishiguro $S$ et al. Endoscopic optical diagnosis provides high diagnostic accuracy of esophageal squamous cell carcinoma. BMC Gastroenterol 2014; 14: 141

[40] Qizilbash AH, Castelli M, Kowalski MA et al. Endoscopic brush cytology and biopsy in the diagnosis of cancer of the upper gastrointestinal tract. Acta Cytol 1980; 24: 313-318

[41] Kaye P, Lindsay D, Madhusudan S et al. Upper GI biopsies for adenocarcinoma - how many biopsies should endoscopists take? Histopathology 2019; 74: 959-963

[42] Malfertheiner P, Megraud F, O'Morain CA et al. European Helicobacter and Microbiota Study Group and Consensus panel. Management of Helicobacter pylori infection - the Maastricht V/Florence Consensus Report. Gut 2017; 66: 6-30

[43] Enomoto $\mathrm{H}$, Watanabe $\mathrm{H}$, Nishikura $\mathrm{K}$ et al. Topographic distribution of Helicobacter pylori in the resected stomach. Eur J Gastroenterol Hepatol 1998; 10: 473-478

[44] Shi H, Xiong H, Qian W et al. Helicobacter pylori infection progresses proximally associated with pyloric metaplasia in age-dependent tendency: a cross-sectional study. BMC Gastroenterol 2018; 18: 158

[45] Sipponen P, Stolte M. Clinical impact of routine biopsies of the gastric antrum and body. Endoscopy 1997; 29: 671-678

[46] Pimentel-Nunes P, Libânio D, Marcos-Pinto R et al. Management of epithelial precancerous conditions and lesions in the stomach (MAPS II): European Society of Gastrointestinal Endoscopy (ESGE), European Helicobacter and Microbiota Study Group (EHMSG), European Society of Pathology (ESP), and Sociedade Portuguesa de Endoscopia Digestiva (SPED) guideline update 2019. Endoscopy 2019; 51: 365-388
[47] Castro R, Esposito G, Libânio D et al. A single vial is enough in the absence of endoscopic suspected intestinal metaplasia - less is more! Scand J Gastroenterol 2019; 54: 673-677

[48] Genta R, Schuler C, Robiou C et al. No association between gastric fundic gland polyps and gastrointestinal neoplasia in a study of over 100,000 patients. Clin Gastroenterol Hepatol 2009; 7: 849-854

[49] Levy M, Bhattacharya B. Sporadic fundic gland polyps with lowgrade dysplasia: a large case series evaluating pathologic and immunohistochemical findings and clinical behavior. Am J Clin Pathol 2015; 144: 592-600

[50] Jalving M, Koornstra JJ, Götz JM et al. High-grade dysplasia in sporadic fundic gland polyps: a case report and review of the literature. Eur J Gastroenterol Hepatol 2003; 15: 1229-1233

[51] Stolte M, Vieth M, Ebert M. High-grade dysplasia in sporadic fundic gland polyps. Eur J Gastroenterol Hepatol 2003; 15: 1153-1156

[52] Ballecer E, Muddasani R, Forman J et al. A rare case of high-grade dysplasia in sporadic fundic gland polyps. Am J Gastroenterol 2018; 113: S1463-S1464

[53] Banks M, Graham D, Jansen M et al. British Society of Gastroenterology guidelines on the diagnosis and management of patients at risk of gastric adenocarcinoma. Gut 2019; 68: 1545-1575

[54] Stolte M, Sticht T, Eidt $S$ et al. Frequency, location, and age and sex distribution of various types of gastric polyp. Endoscopy 1994; 26: 659-665

[55] Daibo M, Itabashi M, Hirota T. Malignant transformation of gastric hyperplastic polyps. Am J Gastroenterol 1987; 82: 1016-1025

[56] Abraham S, Yardley J, Wu T. Hyperplastic polyps of the stomach: associations with histologic patterns of gastritis and gastric atrophy. Am J Surg Pathol 2001; 25: 500-507

[57] Oberhuber G, Stolte M. Gastric polyps: an update of their pathology and biological significance. Virchows Arch 2000; 437: 581-590

[58] Orlowska J, Jarosz D, Pachlewski J et al. Malignant transformation of benign epithelial gastric polyps. Am J Gastroenterol 1995; 90: 21522159

[59] Han A, Sung C, Kim K et al. The clinicopathological features of gastric hyperplastic polyps with neoplastic transformations: a suggestion of indication for endoscopic polypectomy. Gut Liver 2009; 3: 271-275

[60] Seifert E, Gail K, Weismüller J. Gastric polypectomy. Endoscopy 1983; 15: 8-11

[61] Forté E, Petit B, Walter T et al. Risk of neoplastic change in large gastric hyperplastic polyps and recurrence after endoscopic resection. Endoscopy 2020; 52: 444-453

[62] Lang G, Nalbantoglu I, Early D et al. High recurrence rate of large hyperplastic polyps after endoscopic resection. Am J Gastroenterol 2016; 111: \$499

[63] Borch K, Skarsgard J, Franzen L et al. Benign gastric polyps: morphological and functional origin. Dig Dis Sci 2003; 48: 1293

[64] Cristallini E, Ascani S, Bolis G. Association between histologic type of polyp and carcinoma in the stomach. Gastrointest Endosc 1992; 38: 481-484

[65] Kamiya T, Morishita T, Asakura H et al. Long-term follow-up study on gastric adenoma and its relation to gastric protruded carcinoma. Cancer 1982; 50: 2496-2503

[66] Abraham S, Montgomery E, Singh V et al. Gastric adenomas. Am J Surg Pathol 2002; 26: 1276-1285

[67] Laxén F, Sipponen P, Ihamäki T et al. Gastric polyps; their morphological and endoscopical characteristics and relation to gastric carcinoma. Acta Pathol Microbiol Immunol Scand A 1982; 90: 221-228

[68] Nishitani M, Yoshida N, Tsuji S et al. Optimal number of endoscopic biopsies for diagnosis of early gastric cancer. Endosc Int Open 2019; 7: E1683-E1690 
[69] Choi Y, Choi HS, Jeon WK et al. Optimal number of endoscopic biopsies in diagnosis of advanced gastric and colorectal cancer. J Korean Med Sci 2012; 27: 36-39

[70] Vivier-Chicoteau J, Lambert J, Coriat R et al. Development and internal validation of a diagnostic score for gastric linitis plastica. Gastric Cancer 2020; 23: 639-647

[71] Blair VR, McLeod M, Carneiro F et al. Hereditary diffuse gastric cancer: updated clinical practice guidelines. Lancet Oncol 2020; 21: e386-e397

[72] van der Post RS, Vogelaar IP, Carneigo F et al. Hereditary diffuse gastric cancer: updated clinical guidelines with an emphasis on germline CHD1 mutation carriers. J Med Genet 2015; 52: 361-374

[73] Ye Y, Tan S. Endoscopic ultrasound-guided fine-needle aspiration biopsy for diagnosis of gastric linitis plastica with negative malignant endoscopy biopsies. Oncol Lett 2018; 16: 4915-4920

[74] Zhou X, Pan H, Usman A et al. Endoscopic ultrasound-guided deep and large biopsy for diagnosis of gastric infiltrating tumors with negative malignant endoscopy biopsies. World J Gastroenterol 2015; 21: 3607-3613

[75] Liu Y, Chen K, Yan X. Endoscopic ultrasound-guided fine-needle aspiration used in diagnosing gastric linitis plastica: Metastatic lymph nodes can be valuable targets. J Gastroenterol Hepatol 2019; 34: 202-206

[76] Chiyo T, Kobara H, Mori $\mathrm{H}$ et al. Submucosal endoscopic sampling for indefinite gastric linitis plastica infiltrating into the submucosal layer. J Gastrointest Liver Dis 2015; 24: 375-378

[77] Mooney PD, Kurien M, Evans KE et al. Clinical and immunologic features of ultra-short celiac disease. Gastroenterol 2016; 150: 11251134

[78] Bai JC, Ciacci C. World Gastroenterology Organisation Global Guidelines, Celiac disease. J Clin Gastroenterol 2017; 51: 755-768

[79] Rubio-Tapia A, Hill ID, Kelly CP et al. American College of Gastroenterology clinical guideline: diagnosis and management of celiac disease. Am J Gastroenterol 2013; 108: 656-676

[80] Robert ME, Crowe SE, Burgart L et al. Statement on best practices in the use of pathology as a diagnostic tool for celiac disease: a guide for clinicians and pathologists. Am J Surg Pathol 2018; 42: e44-e58

[81] McCarty TR, O'Brien CR, Gremida A et al. Efficacy of duodenal bulb biopsy for diagnosis of celiac disease: a systematic review and metaanalysis. Endosc Int Open 2018; 6: E1369-E1378

[82] Stoven SA, Choung RS, Rubio-Tapia A et al. Analysis of biopsies from duodenal bulbs of all endoscopy patients increases detection of abnormalities but has a minimal effect on diagnosis of celiac disease. Clin Gastroenterol Hepatol 2016; 14: 1582-1588

[83] Shamban L, Sorser S, Naydin S et al. Factors associated with number of duodenal samples obtained in suspected celiac disease. Endosc Int Open 2017; 5: E1220-E1228

[84] Stavropoulos SN, Im GY, Jlayer Z et al. High yield of same-session EUS-guided liver biopsy by 19-gauge FNA needle in patients undergoing EUS to exclude biliary obstruction. Gastrointest Endosc 2012; 75: 310-318

[85] Shuja A, Alkhasawneh A, Fialho A et al. Comparison of EUS-guided versus percutaneous and transjugular approaches for the performance of liver biopsies. Dig Liver Dis 2019; 51: 826-830

[86] Diehl D, Johal A, Khara $\mathrm{H}$ et al. Endoscopic ultrasound-guided liver biopsy: a multicenter experience. Endosc Int Open 2015; 3: E210E215

[87] Sey MS, Al-Haddad M, Imperiale TF et al. EUS-guided liver biopsy for parenchymal disease: a comparison of diagnostic yield between two core biopsy needles. Gastrointest Endosc 2016; 83: 347-352

[88] Pineda J], DiehI DL, Miao CL et al. EUS-guided liver biopsy provides diagnostic samples comparable with those via the percutaneous or transjugular route. Gastrointest Endosc 2016; 83: 360-365
[89] Shah ND, Sasatomi E, Baron TH. Endoscopic ultrasound-guided parenchymal liver biopsy: single center experience of a new dedicated core needle. Clin Gastroenterol Hepatol 2017; 15: 784-786

[90] Nieto J, Khaleel H, Challita Y et al. EUS-guided fine-needle core liver biopsy sampling using a novel 19-gauge needle with modified 1 pass, 1 actuation wet suction technique. Gastrointest Endosc 2018; 87: 469-475

[91] Rombaoa C, Chen C. The safety and feasibility of endoscopic ultrasound-guided parenchymal liver biopsy at a large community hospital. J Can Assoc Gastroenterol 2018; 1: 282

[92] Mok SRS, DiehI DL, Johal AS et al. Endoscopic ultrasound-guided biopsy in chronic liver disease: a randomized comparison of 19-G FNA and 22-G FNB needles. Endosc Int Open 2019; 7: E62-E71

[93] Bazerbachi F, Vargas EJ, Matar R et al. EUS-guided core liver biopsy sampling using a 22-gauge fork-tip needle: a prospective blinded trial for histologic and lipidomic evaluation in nonalcoholic fatty liver disease. Gastrointest Endosc 2019; 90: 926-932

[94] Mohan BP, Shakhatreh M, Garg R et al. Efficacy and safety of EUSguided liver biopsy: a systematic review and meta-analysis. Gastrointest Endosc 2019; 89: 238-246

[95] Hasan MK, Kadkhodayan K, Idrisov E et al. Endoscopic ultrasoundguided liver biopsy using a 22-G fine needle biopsy needle: a prospective study. Endoscopy 2019; 51: 818-824

[96] Ching-Companioni RA, Diehl DL, Johal AS et al. 19G aspiration needle versus $19 \mathrm{G}$ core biopsy needle for endoscopic ultrasound-guided liver biopsy: a prospective randomized trial. Endoscopy 2019; 51 1059-1065

[97] Dumonceau JM, Deprez PH, Jenssen C et al. Indications, results, and clinical impact of endoscopic ultrasound (EUS)-guided sampling in gastroenterology: European Society of Gastrointestinal Endoscopy (ESGE) Clinical Guideline-Updated January 2017. Endoscopy 2017; 49: $695-714$

[98] Oppong KW, Bekkali NLH, Leeds JS et al. Fork-tip needle biopsy versus fine-needle aspiration in endoscopic ultrasound-guided sampling of solid pancreatic masses: a randomized crossover study. Endoscopy 2020; 52: 454-461

[99] Karsenti D, Palazzo L, Perrot B et al. 22G Acquire vs. 20G Procore needle for endoscopic ultrasound-guided biopsy of pancreatic masses: a randomized study comparing histologic sample quantity and diagnostic accuracy. Endoscopy 2020; 52: 747-753

[100] Matsuno J, Ogura T, Kurisu Y et al. Prospective comparison study of Franseen needle and standard needle use for pancreatic lesions under EUS guidance. Endosc Ultrasound 2019; 8: 412-417

[101] Ishikawa T, Kawashima H, Ohno E et al. Clinical impact of EUS-guided fine needle biopsy using a novel Franseen needle for histological assessment of pancreatic diseases. Can J Gastroenterol Hepatol 2019: doi:10.1155/2019/8581743

[102] Facciorusso A, Bajwa HS, Menon K et al. Comparison between 22C aspiration and 22G biopsy needles for EUS-guided sampling of pancreatic lesions: A meta-analysis. Endosc Ultrasound 2020; 9: 167174

[103] Facciorusso A, Wani S, Triantafyllou K et al. Comparative accuracy of needle sizes and designs for EUS tissue sampling of solid pancreatic masses: a network meta-analysis. Gastrointest Endosc 2019; 90: 893-903

[104] Asokkumar R, Yung Ka C, Loh T et al. Comparison of tissue and molecular yield between fine-needle biopsy (FNB) and fine-needle aspiration (FNA): a randomized study. Endosc Int Open 2019; 7: E955E963

[105] van Riet PA, Larghi A, Attili F et al. A multicenter randomized trial comparing a 25-gauge EUS fine-needle aspiration device with a 20gauge EUS fine-needle biopsy device. Gastrointest Endosc 2019; 89: 329-339 
[106] Bang JY, Hebert-Magee S, Navaneethan U et al. EUS-guided fine needle biopsy of pancreatic masses can yield true histology. Gut 2018; 67: 2081-2084

[107] Hedenström P, Demir A, Khodakaram K et al. EUS-guided reverse bevel fine-needle biopsy sampling and open tip fine-needle aspiration in solid pancreatic lesions - a prospective, comparative study. Scand J Gastroenterol 2018; 53: 231-237

[108] Noh DH, Choi K, Gu S et al. Comparison of 22-gauge standard fine needle versus core biopsy needle for endoscopic ultrasound-guided sampling of suspected pancreatic cancer: a randomized crossover trial. Scand J Gastroenterol 2018; 53: 94-99

[109] Cheng B, Zhang Y, Chen Q et al. Analysis of fine-needle biopsy vs fine-needle aspiration in diagnosis of pancreatic and abdominal masses: a prospective, multicenter, randomized controlled trial. Clin Gastroenterol Hepatol 2018; 16: 1314-1321

[110] Tian L, Tang AL, Zhang L et al. Evaluation of 22G fine-needle aspiration (FNA) versus fine-needle biopsy (FNB) for endoscopic ultrasound-guided sampling of pancreatic lesions: a prospective comparison study. Surg Endosc 2018; 32: 3533-3539

[111] Li H, Li W, Zhou QY et al. Fine needle biopsy is superior to fine needle aspiration in endoscopic ultrasound guided sampling of pancreatic masses: a meta-analysis of randomized controlled trials. Medicine (Baltimore) 2018; 97: e0207

[112] Wang J, Zhao S, Chen Y et al. Endoscopic ultrasound guided fine needle aspiration versus endoscopic ultrasound guided fine needle biopsy in sampling pancreatic masses: A meta-analysis. Medicine (Baltimore) 2017; 96: e7452

[113] Khan MA, Grimm IS, Ali B et al. A meta-analysis of endoscopic ultrasound-fine-needle aspiration compared to endoscopic ultrasoundfine-needle biopsy: diagnostic yield and the value of onsite cytopathological assessment. Endosc Int Open 2017; 5: E363-E375

[114] van Riet PA, Erler NS, Bruno MJ et al. Comparison of fine-needle aspiration and fine-needle biopsy devices for endoscopic ultrasoundguided sampling of solid lesions: a systemic review and meta-analysis. Endoscopy 2021; 53: 411-423

[115] Tummala P, Munigala S, Eloubeidi MA et al. Patients with obstructive jaundice and biliary stricture \pm mass lesion on imaging: prevalence of malignancy and potential role of EUS-FNA. J Clin Gastroenterol 2013; 47: 532-537

[116] De Moura DTH, Moura EGH, Bernardo WM et al. Endoscopic retrograde cholangiopancreatography versus endoscopic ultrasound for tissue diagnosis of malignant biliary stricture: Systematic review and meta-analysis. Endosc Ultrasound 2018; 7: 10-19

[117] Moura DTH, de Moura EGH, Matuguma SE et al. EUS-FNA versus ERCP for tissue diagnosis of suspect malignant biliary strictures: a prospective comparative study. Endosc Int Open 2018; 6: E769E777

[118] Sadeghi A, Mohamadnejad M, Islami F et al. Diagnostic yield of EUSguided FNA for malignant biliary stricture: a systematic review and meta-analysis. Gastrointest Endosc 2016; 83: 290-298

[119] Sun X, Zhou Z, Tian J et al. Is single-operator peroral cholangioscopy a useful tool for the diagnosis of indeterminate biliary lesion? A systematic review and meta-analysis Gastrointest Endosc 2015; 82: 7987

[120] Badshah MB, Vanar V, Kandula M et al. Peroral cholangioscopy with cholangioscopy-directed biopsies in the diagnosis of biliary malignancies: a systemic review and meta-analysis. Eur J Gastroenterol Hepatol 2019; 31: 935-940

[121] Kulpatcharapong S, Pittayanon R, Kerr SI et al. Diagnostic performance of different cholangioscopes in patients with biliary strictures: a systematic review. Endoscopy 2020; 52: 174-185
[122] Korrapati P, Ciolino ], Wani S et al. The efficacy of peroral cholangioscopy for difficult bile duct stones and indeterminate strictures: a systematic review and meta-analysis. Endosc Int Open 2016; 4: E263-E275

[123] de Oliveira PVAG, de Moura DTH, Ribeiro IB et al. Efficacy of digital single-operator cholangioscopy in the visual interpretation of indeterminate biliary strictures: a systematic review and meta-analysis. Surg Endosc 2020; 34: 3321-3329

[124] Gerges C, Beyna T, Tang RSY et al. Digital single-operator peroral cholangioscopy-guided biopsy versus ERCP-guided brushing for indeterminate biliary strictures: a prospective, randomized multicenter trial (with video). Gastrointest Endosc 2020; 91: 1105-1113

[125] Lee YN, Moon JH, Choi HJ et al. Tissue acquisition for diagnosis of biliary strictures using peroral cholangioscopy or endoscopic ultrasound-guided fine-needle aspiration. Endoscopy 2019; 51: 50-59

[126] Barkun A, Liu J, Carpenter S et al. Update on endoscopic tissue sampling devices. Gastrointest Endosc 2006; 63: 741-745

[127] Sharaf RN, Shergill AK, Odze RD et al. Endoscopic mucosal tissue sampling. Gastrointest Endosc 2013; 78: 216-224

[128] Sussman DA, Deshpande AR, Shankar U et al. Comparison of performance characteristics of oval cup forceps versus serrated jaw forceps in gastric biopsy. Dig Dis Sci 2016; 61: 2338-2343

[129] Danesh B], Burke M, Newman J et al. Comparison of weight, depth, and diagnostic adequacy of specimens obtained with 16 different biopsy forceps designed for upper gastrointestinal endoscopy. Gut 1985; 26: 227-231

[130] Bernstein DE, Barkin JS, Reiner DK et al. Standard biopsy forceps versus large-capacity forceps with and without needle. Gastrointest Endosc 1995; 41: 573-576

[131] Woods KL, Anand BS, Cole RA et al. Influence of endoscopic biopsy forceps characteristics on tissue specimens: results of a prospective randomized study. Gastrointest Endosc 1999; 49: 177-183

[132] van Riet PA, Quispel R, Cahen DL et al. Diagnostic yield and agreement on fine-needle specimens from solid pancreatic lesions: comparing the smear technique to liquid-based cytology. Endosc Int Open 2020; 8: E155-E162

[133] Kopelman Y, Marmor S, Ashkenazi I et al. Value of EUS-FNA cytological preparations compared with cell block sections in the diagnosis of pancreatic solid tumours. Cytopathology 2011; 22: 174-178

[134] Hikichi T, Irisawa A, Bhutani MS et al. Endoscopic ultrasound-guided fine-needle aspiration of solid pancreatic masses with rapid on-site cytological evaluation by endosonographers without attendance of cytopathologists. J Gastroenterol 2009; 44: 322-328

[135] Nayar MK, Chatterjee S, Wadehra V et al. Does on-site adequacy assessment by cytotechnologists improve results of EUS guided FNA of solid pancreaticobiliary lesions? JOP 2013; 14: 44-49

[136] Alsohaibani F, Girgis S, Sandha GS. Does onsite cytotechnology evaluation improve the accuracy of endoscopic ultrasound-guided fine-needle aspiration biopsy? Can J Gastroenterol 2009; 23: 26-30

[137] Ecka RS, Sharma M. Rapid on-site evaluation of EUS-FNA by cytopathologist: an experience of a tertiary hospital. Diagn Cytopathol 2013; 41: 1075-1080

[138] Da Cunha Santos G, Saieg MA. Preanalytic specimen triage: Smears, cell blocks, cytospin preparations, transport media, and cytobanking. Cancer Cytopathol 2017; 125: 455-464

[139] Hassan C, Ponchon T, Bisschops R et al. European Society of Gastrointestinal Endoscopy (ESGE) Publications Policy - Update 2020. Endoscopy 2020; 52: 123-126 